\title{
INTERFACE BOND BEHAVIOUR BETWEEN CIRCULAR STEEL TUBE AND LIGHTWEIGHT AGGREGATE CONCRETE
}

\author{
Z.Q. Fu' ${ }^{1}$, H.B. Ge ${ }^{2, *}$, B.H. Ji ${ }^{1}$ and J.J. Chen ${ }^{1}$ \\ ${ }^{1}$ School of Civil and Transportation Engineering, Hohai University, Nanjing 210098, China \\ ${ }^{2}$ Department of Civil Engineering, Meijo University, Nagoya 468-8502, Japan \\ *(Corresponding author: E-mail: gehanbin@meijo-u.ac.jp)
}

Received: 19 December 2016; Revised: 22 July 2017; Accepted: 19 November 2017

\begin{abstract}
To ascertain the nature of the interface bond behaviour of lightweight aggregate concrete-filled steel tubes (LACFSTs), 27 specimens were tested by push-out loading and four of them were subjected to repeated push-out loading. Influence factors such as lightweight aggregate concrete strength, concrete vibration and curing method, steel surface conditions, slenderness ratio, and diameter-to-thickness ratio were considered. The bond slip process and strength were analysed and a formula was proposed to calculate the bond strength of the LACFSTs. The results show that the bond-slip curve can take one of two forms: one with an obvious peak, the other without, and each one manifests three different trends after reaching ultimate load. According to the test results, the bond strength is independent of the lightweight aggregate concrete strength. Higher diameter-to-thickness ratios cause a reduction in the bond strength. A good quality of concrete vibration and curing can improve the bond strength. The bond strength after the first of the repeated push-out tests is the largest. In the same push-out direction, the bond strength decreases as the push-out time increases, and the load-slip curves are similar among all samples tested. The comparisons between test results and calculations show that the proposed formula has a good accuracy.
\end{abstract}

Keywords: Lightweight aggregate concrete, concrete-filled steel tube, push-out test, bond strength, bond-slip

DOI: $10.18057 /$ IJASC.2018.14.3.7

\section{INTRODUCTION}

Concrete filled steel tube (CFST) fully utilizes the tensile- compressive properties of steel and compressive strength of concrete, and has a wide range of applications in various types of structures [1-2]. Research has also been carried out into the design and construction of steel tube concrete structures [3-4]. The demands of different applications, section shapes, and categories of in-filled concrete contribute to various types of CFST including: square CFST, circular CFST, high-strength concrete filled steel tubes, recycled concrete filled steel tubes, and so on. According to the stress acting on the section, CFST can be classified into partially-filled steel tubes, confined concrete-filled steel tubes, and normal CFST, depending on whether the stress acts only on the steel tube, coral concrete or the combined section as a whole [5-7]. Lightweight aggregate concrete-filled steel tube (LACFST) is one type studied here. Previous studies show that the behaviour of LACFSTs is excellent and can replace normal CFSTs [7-9]. Due to their lighter weight, it can expect a more significant advantage in application [10].

As a type of composite structures, the bond strength directly affects whether the two materials can work together or not [11]. Due to the lack of accurate constitutive relationships, many studies assume that there is no slip between the steel tube and the concrete under load. To describe the bond behaviour, the interface bond slip of CFSTs was studied [12-13]. Early studies mostly involved normal CFST. In recent years with the application of research into various kinds of new composite structures, such as recycled aggregate CFSTs, high-strength CFSTs, etc., the corresponding bond slip behaviour was also studied. Some of the studies examined the change of interface bond behaviour of CFSTs after fire or fatigue load action [14-15]. At present, there are 
two main methods used to test the interface bond slip in a CFST. Push-off tests, with the load acting on the whole section, can be used to simulate the actual change in a structure while only the ultimate bond strength can be tested by this method [16]. The Push out test is adopted by most studies because it can measure the bond strength in the whole loading process [17-18]. Tao et al. [13] prepared a total of 24 specimens to consider influence of various parameters, including the section shape, steel type, concrete type, concrete age and interface type. The results showed that the bond strength declined dramatically with increasing of tube size and the concrete age. Pre-stressing concrete was adopted by Chen et al. [17] and 20 specimens were fabricated to study the influences of the pre-stress on the bond strength of steel-concrete interface. The bond strength of CFST with pre-stressing concrete was approximately 1.2 3.3 times than that with normal concrete. A new stiffening system was proposed by Chen et al. [19] to improve the bond strength at the steel-concrete interface and the degree of improvement increased with decreasing tab stiffener spacing. Tests carried out by researchers [20-26] mainly focused on the section shape, steel grade, concrete strength, number of specimens, etc., and the bond strength concluded from the tests above ranges from 0.03 to 3.29 , showing a distinct discreteness.

So far, it is still not possible to provide reliable equations to predict the bond strength in CFST columns because of the numerous influencing parameters and uncertainties. For simplification purposes, existing design codes only specify constant design bond strengths for CFST columns based on previous test data. In Europe standard [27] and American standard [28], the specified design bond strength is $0.4 \mathrm{MPa}$ for both circular and rectangular CFST columns. In contrast, the specified bond strength values in Japan standard [29] are 0.225 MPa and 0.15 MPa for circular and rectangular CFST columns, respectively. In China standard [30], the bond strength ranges from 0.40 0.60 considering different concrete grades. To study the mechanical properties of lightweight concrete filled steel tubes, an experimental study of bond slip was carried out considering different factors influencing the bond strength.

\section{EXPERIMENTAL PROGRAM}

\subsection{Material and Specimens}

The coarse aggregate used in this lightweight aggregate concrete is ceramsite. The bulk density is $814 \mathrm{~kg} / \mathrm{m}^{3}$, the cylindrical compressive strength is $8.5 \mathrm{MPa}$, and the water absorption is $6 \%$ at one hour. Ordinary Portland cement was used in the concrete. The fine aggregate is a kind of medium sand with a fineness modulus of 2.6 and a bulk density of $2600 \mathrm{~kg} / \mathrm{m}^{3}$. Slag powder and JM-B water reducer were used to improve the concrete mechanical properties. Three strength types of lightweight aggregate concretes (LAC) numbered: CL1, CL2, and CL3, were considered. According to the relevant Chinese standards, compression tests were carried out on a number of standard cubes $\left([150 \times 150 \times 150] \mathrm{mm}^{3}\right)$ to determine the concrete grade and prisms $([150 \times 150 \times$ $\left.300] \mathrm{mm}^{3}\right)$ and determine the compressive strength $\left(f_{c k}\right)$ and elastic modulus $\left(E_{c}\right)$ of the unconfined concrete. The concrete mix proportions and mechanical properties are given in Table 1 .

Table 1. Mixture Ratio and Mechanical Properties of Lightweight Aggregate Concrete

\begin{tabular}{ccccccccc}
\hline \multirow{2}{*}{ Number } & \multicolumn{6}{c}{ Mass in per cubic meter of concrete/ kg } & \multirow{2}{*}{$f_{c k}(\mathrm{MPa})$} & \multirow{2}{*}{$E_{c}(\mathrm{MPa})$} \\
\cline { 2 - 7 } & Cement & Ceramsite & Sand & Slag & Water & Water reducer & & \\
\hline CL1 & 460 & 670 & 650 & - & 203.5 & - & 28.71 & $19.50 \times 10^{3}$ \\
CL2 & 387 & 645 & 643 & 43 & 150 & 3.8 & 30.71 & $23.84 \times 10^{3}$ \\
CL3 & 450 & 650 & 650 & 50 & 125 & 6.8 & 37.38 & $24.83 \times 10^{3}$ \\
\hline
\end{tabular}


Straight welded steel tube Q235 was used in the test. A group of three standard specimens was tested to determine the tensile strength of the steel and the section thickness of each steel tube fitted the standard specimen dimensions. The test method followed the Chinese Standard for "GB/T228-2002 Metallic materials-Tensile testing at ambient temperature" [31]. The steel specimen is shown in Figure 1. The yield strengths $\left(f_{y}\right)$ of the steel with thicknesses of $2.5 \mathrm{~mm}$ and $4.0 \mathrm{~mm}$ were 305.6 MPa and 274.7 MPa, respectively, and test results are shown in Figure 2.

A $50 \mathrm{~mm}$ length at the upper end of each steel tube was left empty. After pouring the LAC, a 50 mm diameter vibrator was used to compact the concrete, except in one group of specimens which were manually vibrated. Some 10 days of curing later, the bottom of the column was smoothed with fresh cement paste. The details of the test specimens are shown in Table 2, where group A was designed for comparison of different lightweight aggregate concrete strengths, group B for comparison of different curing techniques, group $\mathrm{C}$ for comparison of different pouring techniques, group D for comparison of different surface conditions, group $\mathrm{E}$ for comparison of different slenderness ratios, and group $\mathrm{F}$ for comparison of different diameter to thickness ratios.

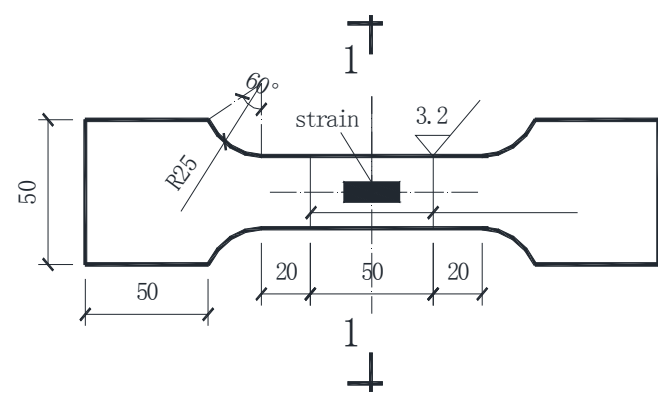

Figure 1. Steel Tensile Specimen (Unit:mm)

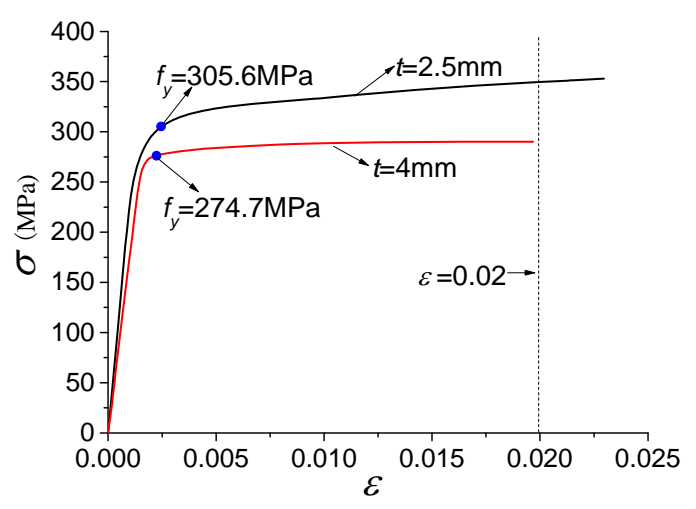

Figure 2. Stress-Strain Curve of Steel

\section{$2.2 \quad$ Test Instruments and Procedure}

Figure 3 shows the loading and measurement system. The load was applied by hydraulic jack with a maximum load range of $3000 \mathrm{kN}$ and measured by a pressure sensor with maximum range equivalent to $500 \mathrm{kN}$. To measure the relative displacement of the steel tube and the core concrete, two displacement transducers were arranged at the bottom end of the steel tube column on magnetic meter bases. Throughout the test, the data were continuously collected by a data acquisition system which was composed of TS3890 dynamic strain gauges, gauge readers, and a personal computer. 


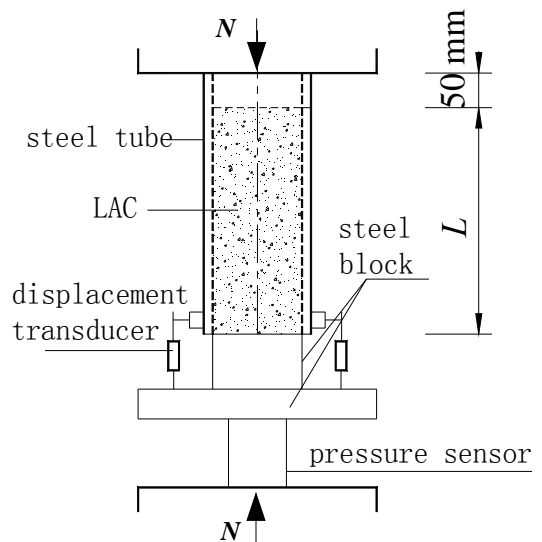

(a) Schematic of the Device

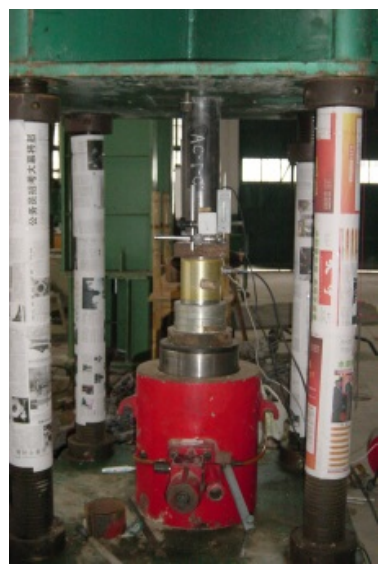

(b) Loading Picture

Figure 3. Loading and Measurement System

Before testing, a pre-load of $1 \mathrm{kN}$ to $2 \mathrm{kN}$ was applied to ensure that all component of the loading and measurement system were brought into close contact. Then this seating load was removed and the test started. The specimens were loaded at rate of $1 / 20$ of the predicted ultimate load at the beginning. Each load was maintained for about 2-3 minutes to enable development of the full associated deformation. When obvious non-linear sliding between the steel tube and concrete was observed, the samples were loaded slowly and continuously. The test was stopped when the concrete underwent an apparent slip displacement. Four specimens were selected for reloading in the opposite direction and this procedure was repeated for a total of four load cycles.

\section{DISCUSSIONS OF INITIAL PUSH-OUT TESTS RESULTS}

\subsection{Testing process and slip curves}

At the beginning of the test, the displacement increased slowly and minimal slip occurred. On approaching the failure load, brittle acoustic emissions from the concrete could be heard. The displacement increased with the load increasing and the acoustic emissions from the concrete also increased in frequency and intensity. After the maximum value of load was conducted, the load plateaued for a period of time while the displacement still increased. Then, the load began to decrease as the displacement still increased. The displacement reached the maximum when the core concrete was pushed out. For the failure specimens, concrete showed obvious slippage with crushing at one end. Figure 4 shows the failed specimens after a push-out test. No local buckling appeared on the steel tube, which indicated that the steel tube restrained concrete effectively.

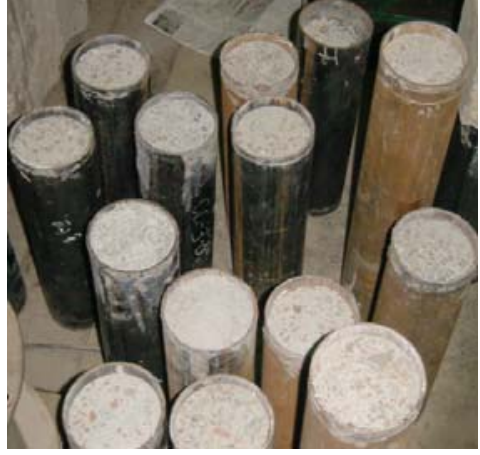

(a) Tested Specimens

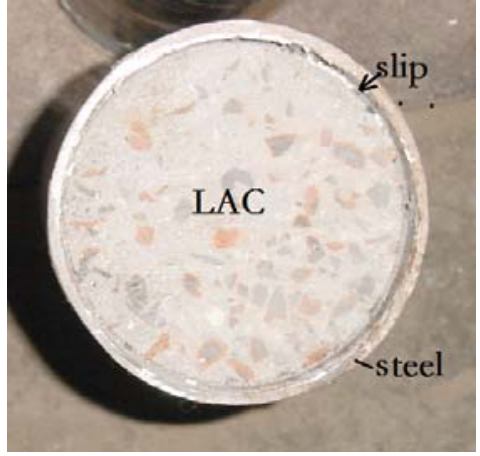

(b) Slip of the End

Figure 4. Specimens after Testing 
Table 2. Dimensions and Results of Tested Specimens.

\begin{tabular}{|c|c|c|c|c|c|c|c|c|c|c|}
\hline Specimen & $\begin{array}{c}\text { Tube size } \\
\quad(\mathrm{mm}) \\
D \times t \times L\end{array}$ & $\begin{array}{c}\text { Slenderness } \\
\text { ratio } \\
4 L / D\end{array}$ & $\begin{array}{c}\text { Diameter } \\
\text { to } \\
\text { thickness } \\
\text { ratio } D / t\end{array}$ & $\begin{array}{l}\text { Concrete } \\
\text { strength } \\
f_{c k}(\mathrm{MPa})\end{array}$ & $\begin{array}{l}\text { Ultimate } \\
\text { load } \\
(\mathrm{kN})\end{array}$ & $\begin{array}{l}\text { Bond } \\
\text { strength } \\
\text { (MPa) }\end{array}$ & $\begin{array}{c}\text { Average } \\
\text { strength } \\
(\mathrm{MPa})\end{array}$ & $\begin{array}{l}\text { Concrete } \\
\text { vibration }\end{array}$ & Curing & Surface \\
\hline A-1-a & $114 \times 4 \times 350$ & 12.28 & 28.5 & 28.71 & 169.5 & 1.45 & & & & \\
\hline A-1-b & $114 \times 4 \times 350$ & 12.28 & 28.5 & 28.71 & 162.9 & 1.40 & 1.42 & Vibrator & Natural & Smooth \\
\hline A-1-C & $114 \times 4 \times 350$ & 12.28 & 28.5 & 28.71 & 163.5 & 1.40 & & & & \\
\hline A-2-a & $114 \times 4 \times 350$ & 12.28 & 28.5 & 30.71 & 181.6 & 1.56 & & & & \\
\hline A-2-b & $114 \times 4 \times 350$ & 12.28 & 28.5 & 30.71 & 181.8 & 1.56 & 1.52 & Vibrator & Natural & Smooth \\
\hline A-2-c & $114 \times 4 \times 350$ & 12.28 & 28.5 & 30.71 & 167.2 & 1.43 & & & & \\
\hline A-3-a & $114 \times 4 \times 350$ & 12.28 & 28.5 & 37.38 & 161.7 & 1.39 & & & & \\
\hline A-3-b & $114 \times 4 \times 350$ & 12.28 & 28.5 & 37.38 & 165.3 & 1.42 & 1.39 & Vibrator & Natural & Smooth \\
\hline A-3-c & $114 \times 4 \times 350$ & 12.28 & 28.5 & 37.38 & 158.4 & 1.36 & & & & \\
\hline B-4-a & $114 \times 4 \times 350$ & 12.28 & 28.5 & 28.71 & 145.8 & 1.25 & & & & \\
\hline B-4-b & $114 \times 4 \times 350$ & 12.28 & 28.5 & 28.71 & 150.1 & 1.29 & 1.26 & Vibrator & $\begin{array}{l}\text { Sealed } \\
\text { curing }\end{array}$ & Smooth \\
\hline B-4-c & $114 \times 4 \times 350$ & 12.28 & 28.5 & 28.71 & 145.2 & 1.25 & & & & \\
\hline C-5-a & $114 \times 4 \times 350$ & 12.28 & 28.5 & 28.71 & 148.0 & 1.27 & & & & \\
\hline C-5-b & $114 \times 4 \times 350$ & 12.28 & 28.5 & 28.71 & 153.9 & 1.32 & 1.28 & Manual & Natural & Smooth \\
\hline C-5-c & $114 \times 4 \times 350$ & 12.28 & 28.5 & 28.71 & 147.1 & 1.26 & & & & \\
\hline D-6-a & $114 \times 4 \times 350$ & 12.28 & 28.5 & 28.71 & 291.7 & 2.50 & & & & \\
\hline D-6-b & $114 \times 4 \times 350$ & 12.28 & 28.5 & 28.71 & 273.4 & 2.35 & 2.45 & Vibrator & Natural & Rough \\
\hline D-6-c & $114 \times 4 \times 350$ & 12.28 & 28.5 & 28.71 & 289.8 & 2.49 & & & & \\
\hline E-7-a & $114 \times 4 \times 490$ & 17.19 & 28.5 & 28.71 & 318.4 & 1.95 & & & & \\
\hline E-7-b & $114 \times 4 \times 490$ & 17.19 & 28.5 & 28.71 & 370.4 & 2.27 & 2.09 & Vibrator & Natural & Rough \\
\hline E-7-c & $114 \times 4 \times 490$ & 17.19 & 28.5 & 28.71 & 336.1 & 2.06 & & & & \\
\hline E-8-a & $114 \times 4 \times 780$ & 27.37 & 28.5 & 28.71 & 380.2 & 1.46 & & & & \\
\hline E-8-b & $114 \times 4 \times 780$ & 27.34 & 28.5 & 28.71 & 362.0 & 1.39 & 1.46 & Vibrator & Natural & Rough \\
\hline E-8-C & $114 \times 4 \times 780$ & 27.37 & 28.5 & 28.71 & 400.4 & 1.54 & & & & \\
\hline F-9-a & $114 \times 2.5 \times 350$ & 12.28 & 45.6 & 28.71 & 184.5 & 1.53 & & & & \\
\hline F-9-b & $114 \times 2.5 \times 350$ & 12.28 & 45.6 & 28.71 & 174.2 & 1.45 & 1.48 & Vibrator & Natural & Rough \\
\hline F-9-c & $114 \times 2.5 \times 350$ & 12.28 & 45.6 & 28.71 & 177.7 & 1.47 & & & & \\
\hline
\end{tabular}

Notes: (1) $D$ is the external diameter, $t$ is the thickness, and $L$ is the length of the tube.

(2) $f_{c k}$ is the axial compressive strength of the lightweight aggregate concrete.

(3) The bond strength $\tau$ is given by $\tau=N_{u} /(\pi L d)$, where $N_{u}$ is the ultimate load and $d$ is the inner diameter of the tube.

The load-slip curves from initial push-out tests are shown in Figure 5. The corresponding ultimate load and bonding strength are shown in Table 2. The relative slip of concrete increased linearly and slowly with a sharply increasing load at the beginning of test. When the load approached its ultimate value, the slip grew rapidly, indicating that the bond between the lightweight aggregate concrete and the steel tube began to be damaged. After the ultimate load was reached, the slip increased quickly and showed different load-displacement trends.

\subsection{Bond Slip Process}

Figure 5 shows several different types $S$ - $N$ curves. In order to find the load-slippage rule, the bond slip process and the slip mechanism were analyzed.

For the LACFSTs, the bonding force is similar to that of normal CFSTs, and includes the following components: the chemical cementing force at the interface between the cement and the steel pipe, the mechanical interaction force between the concrete and the rough surface of the steel, and the friction at the surface. The chemical cementing force is very small and determined by the concrete properties. The mechanical interaction force generates mainly due to the shearing resistance of the concrete, which depends on the roughness of the steel surface and the shear strength of the concrete. The friction is proportional to the friction coefficient and the pressure on the contact surface. The 
friction coefficient depends on the roughness of the interface between the steel tube and the concrete, and the pressure refers to the restriction imposed by the steel tube on the concrete.

The axial load only acts on the concrete section in the push-out test. Therefore, the longitudinal force is transmitted from the concrete to the steel tube because of the bonding between concrete and steel. Meanwhile, the steel tube is subject to transverse extrusion of concrete under axial load which results in the biaxial stress state of the steel tube. This causes a reduction in the normal constraint capacity which influences the friction on the interface. Due to the non-uniform pipe diameter, the variation was defined to be a macro-dimensional deviation by Virdi [32]. If concrete slipping causes movement to a smaller diameter section of steel tube, the constraint effect increases and friction is enhanced. Before slipping, the bond strength is mainly composed of the chemical cementing force and the mechanical interaction.

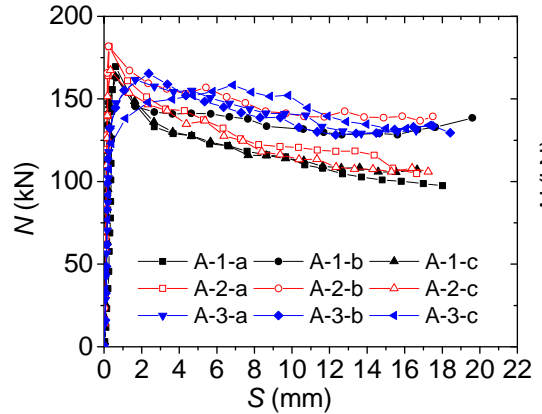

(a) Effect of Concrete Strength

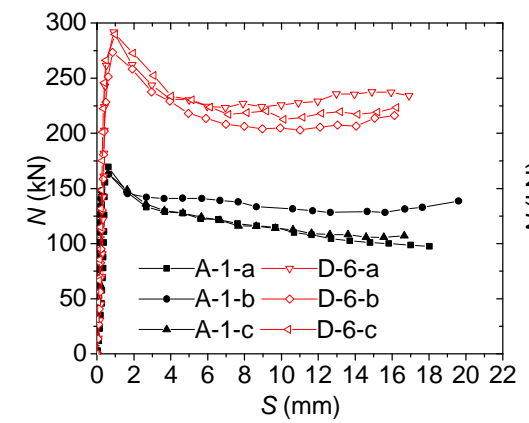

(d) Effect of Steel Surface

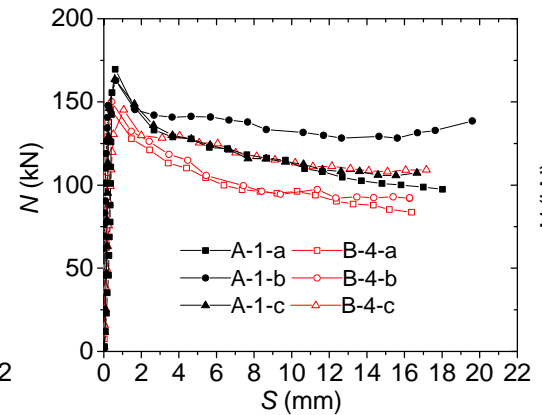

(b) Effect of Curing Conditions

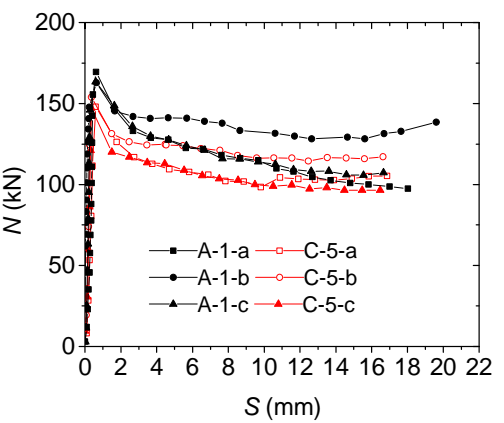

(c) Effect of Pouring Method

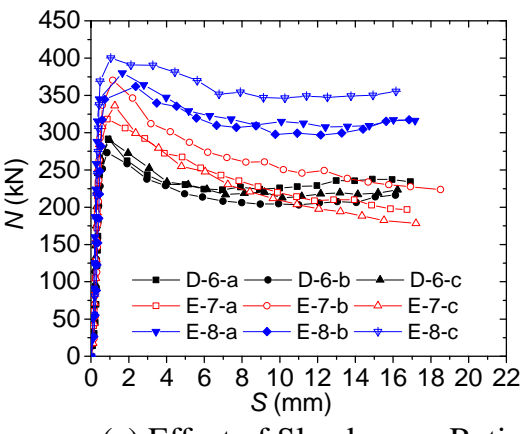

(e) Effect of Slenderness Ratio

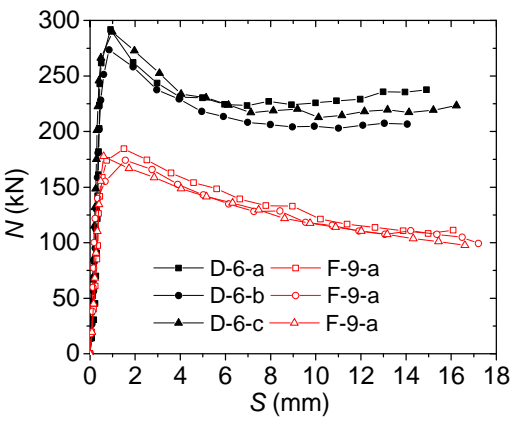

(f) Effect of $D / t$

Figure 5. Load $(N)$-Slip $(S)$ Curves: Push-out Tests

Figure 6 shows one typical bond-slip curve and different stages in the slipping process of a push-out test. At the beginning, the bonding stress is mainly provided by the chemical cementing force with no slip between concrete and steel (point A). As the load increased, a little slip occurred at the two ends of the specimens where the cementing force vanishes. Because the top end is loaded and the bottom end is unconstrained, the mechanical interaction force begins to work at the two ends (point B). Then, the slip at both ends increases and expands to the middle section. The cementing force exists only at the middle section where there is no relative slip. The bonding force of the other parts is mainly provided by the mechanical interaction force (point $\mathrm{C}$ ). When the cementing force and mechanical interaction force reach the maximum value, the load reached failure (or ultimate) load $\boldsymbol{N}_{\boldsymbol{u}}$ (point D), too. When the cementing force is broken completely, relative slip occurs over the whole interface between the steel tube and concrete core. The mechanical interaction also decreases upon large slip and the frictional force appears (point D). Then the mechanical interaction force is broken completely, and the slip increases quickly even as the load changes less (point F). 


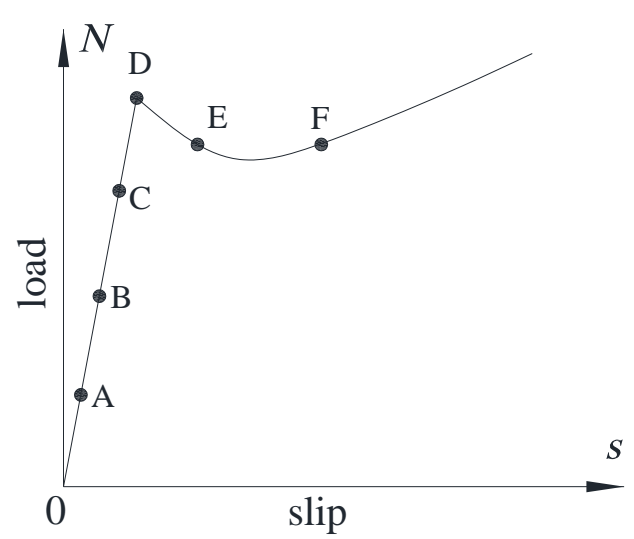

Figure 6. Bond-Slip Process

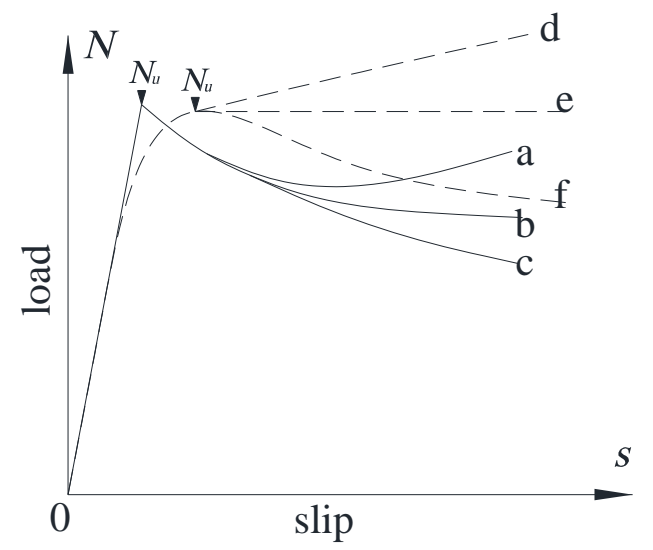

Figure 7. Classifications of Load-Slip Curves

Based on the test results in Figure 5, two classifications of load-slip curves can be seen: one has an obvious peak, the other doesn't, as shown in Figure 7. When there is no slip between the steel tube and the concrete, the bonding capacity consists of the cementing force and the mechanical interaction, which matches the friction force after slipping. If the sum of the cementing force and the mechanical interaction exceeds the initial friction force, the initial friction force cannot balance the bonding capacity before obvious slip occurs and the curves descend immediately with the appearance of a peak point. Otherwise, the curves ascend after obvious slip. However, the initial friction decreases during slippage because the friction reduces the roughness of the interface, which results in an inflection point, but not an obvious peak.

Based on the behavior after reaching the ultimate load, three types of curve are proposed (Figure 7). The macro-dimensional deviation causes an increase in the frictional force. If the macro-dimensional deviation is large, the increase in the friction is higher than the reduction in the initial friction, which causes the curve to have an ascending trend (lines a and d). Otherwise, the increase in friction is lower than the reduction therein, and the curve has a descending trend (lines $\mathrm{c}$ and $\mathrm{f}$ ). In the situation intermediate to the aforementioned scenarios, the curve has an aclinic trend (lines b and e).

\subsection{Effects of Main Factors on Average Strength}

Table 2 shows the bond strength of specimens with different factors and Figure 5 shows the comparison of bonding process. Based on these two, the average bond strength of each group specimens is shown in Figure 8.

\subsubsection{Effect of concrete strength}

The concrete strength of groups A-1, A-2, and A-3 are 28.71 MPa, 30.71 MPa, and 37.38 $\mathrm{MPa}$, respectively. The corresponding bond strengths are $1.43 \mathrm{MPa}$, 1.52 $\mathrm{MPa}$, and 1.39 $\mathrm{MPa}$, which show no obvious trend. The results indicate that the bond stress is independent of concrete strength. This is consistent with the studies of normal CFST tests by Virdi [32] and Liu et al. [33]. Shakir-Khalil [34] also proved that the data from normal CFST tests was scattered. However, Xue et al. [35], through a specimen test study, proposed that a higher concrete strength could increase the bond strength of normal CFSTs. The results showed that the bond strengths were $0.45 \mathrm{MPa}$, $0.56 \mathrm{MPa}, 0.59 \mathrm{MPa}$ and $0.60 \mathrm{MPa}$ (the surface was treated by derusting machine) corresponding to concrete cube strengths of $41.9 \mathrm{MPa}, 53.1 \mathrm{MPa}, 77.8 \mathrm{MPa}$ and $83.7 \mathrm{MPa}$. However, the increase was not obvious especially for the high strength concrete. 


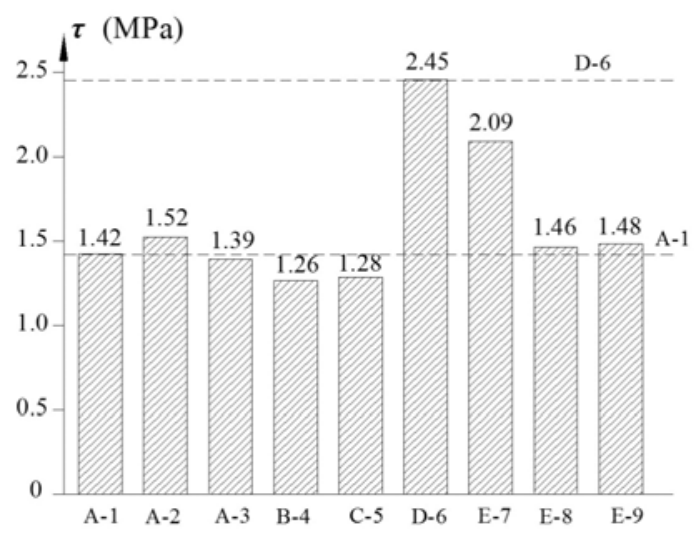

Figure 8. Comparison of Bond Strength

\subsubsection{Effect of concrete curing condition}

Comparison of specimens A-1 and B-4 shows the influence of concrete curing conditions on bond strength: group A-1 was cured under natural conditions while group B-4 was cured under sealed condition. As shown in Figure 8, bond strength under a natural curing condition was higher than that under sealed curing conditions, which matched normal CFSF data from Xue et al. [35]. Some researchers thought that the concrete shrinkage caused a tendency to separation between the concrete and steel and reduced the bond strength [33-35]. In fact, the concrete and steel only tended to separate, but did not do so completely. The tendency to separate causes tensile stress which is smaller than the cementing stress. When the load acts on the section, the transverse strain in the concrete produces a compressive stress in the steel, but some of the compressive stress is offset by the tensile stress caused by the tendency to separate.

\subsubsection{Effect of concrete pouring method}

Concrete in specimens A-1 and C-5 was vibrated by mechanical vibrator and manual, respectively. Figure 8 shows that the specimens vibrated mechanically have a higher bond strength than those compacted manually. The study of normal CFSTs by Virdi [32] also showed that adequate vibration could make the concrete denser and guaranteed that the steel tube and concrete would bond together to increase the bond strength. Otherwise, some clearance might remain between the two materials, which reduced the bond strength.

\subsubsection{Effect of steel surface appearance}

Specimens in group A-1, with their smooth steel surface, had a lower bond strength than specimens in D-6 with a rough steel surface (Figure 8). This is because a rough surface can increase the mechanical interaction force and the friction. The same results from tests on normal CFSTs were also proposed by Shakir-Khalil [34] and Xue et al. [35].

\subsubsection{Effect of slenderness ratio}

In order to avoid local buckling of steel, the slenderness ratio of the walls must satisfy the stipulated limiting value. Slenderness ratio can be expressed as $4 \mathrm{~L}_{0} / \mathrm{D}$ where $\mathrm{L}_{0}$ is the interface length between the concrete and steel tube, and $\mathrm{D}$ is the external diameter of the steel tube. The slenderness ratios of specimens D-6, E-7, and E-8 were 12.28, 17.19, and 27.37, respectively. As shown in Figure 4 and Figure 5, specimens with a higher slenderness ratio sustained a higher 
ultimate load but had a lower bond strength. The study of normal CFSTs by Virdi [32] and Liu et al. [33] showed the opposite trend with a minor increase in the slenderness ratio arrangement from 4 to 12. The results by Shakir-Khalil [34] showed that the slenderness ratio had no obvious influence on bond strength. Xue et al. [36] also found that the bond strength decreased with increasing slenderness ratio under an eccentric load which was similar to the results of these tests. Because the surface of groups D and E was rough, another three specimens were tested with smooth surface. The concrete strength was $31.35 \mathrm{MPa}$. The bond strength were $1.56 \mathrm{MPa}, 1.57 \mathrm{MPa}$ and $1.21 \mathrm{MPa}$ corresponding to slenderness ratios of 12.28, 17.19 and 27.36. The results showed that the larger slenderness ratio had far smaller bond strength and the change of bond strength was not obvious when the slenderness ratio was small (less than 12). More detailed studies about the effects of slenderness ratio are needed.

\subsubsection{Effect of diameter to thickness ratio}

The diameter to thickness ratio reflects the strength of the steel tube to some extent, which can be expressed as D/t where $\mathrm{D}$ is the external diameter of the steel tube, and $\mathrm{t}$ is the thickness of the tube. The diameters to thickness ratio of specimens D-6 and F-9 were 28.5 and 45.6, respectively. The test results showed that the larger the diameter to thickness ratio, the lower the bond strength. Roeder et al. [12] also got the same results when studying normal CFSTs, but the results from normal CFSTs proposed by Virdi [32] indicated that the diameter-to-thickness ratio influenced bond strength less and the test results were scattered.

\section{DISCUSSION OF REPEATED PUSH-OUT TEST RESULTS}

Repeated push-out tests were conducted on four specimens (A-1-c, A-3-a, C-5-c and D-6-a). After the initial push-out test, the lightweight aggregate concrete slipped from the bottom of the steel tube to the upper end and the empty space changed from upper to bottom end. Then, take off the specimen from the loading system and reverse the two end of specimen to make the empty space at the upper end. A repeated loading process of initial push-out testing was conducted on the reversed specimen. The push-out test process had four load cycles in two directions containing the initial one, which was called the repeated push-out test here.

The load-slip curves of the repeated push-out tests are shown in Figure 9, where $n$ is the number of cycles. Figure 9 shows that the ultimate load of $n=1$ is the largest. For push-out at $n=1$, the bond strength is provided by a cementing force and mechanical interaction. In other push-out tests, the cementing force is destroyed and the mechanical interaction is reduced by the previous slippage. The bond strength is mainly offered by the friction which is also reduced because of the smoother interface caused by slippage. Through the analysis of normal CFSTs, such a friction reduction was also proved by Xue et al. [35]. It also causes, in the same push-out direction as $n=1,3$ or $n=2$, 4, the bond strength to decrease as the number of cycles increases. Generally, it is considered that the roughness of interface reduces more with increasing slip and cycling time. However, the test results showed that the bond strength at $n=4$ was higher than that at $n=3$.

After reaching the ultimate load, the load-slip curves for push-out in the same direction had similar trends: $n=3$ tended to $n=1$, and $n=4$ tended to $n=2$. The ultimate load for push-out corresponding to a larger number of cycles in the same direction was smaller. It was easier for the increase in friction caused by macro-dimensional deviation to balance the ultimate load. This resulted in a rising trend of the curves for $n=3,4$ compared to those of $n=1,2$, and caused the curves for push-out in the same direction to come together. However, these were not mentioned in the studies of normal CFST tests, but the tests result figures by Xue et al. also showed the similar conclusions [35]. 


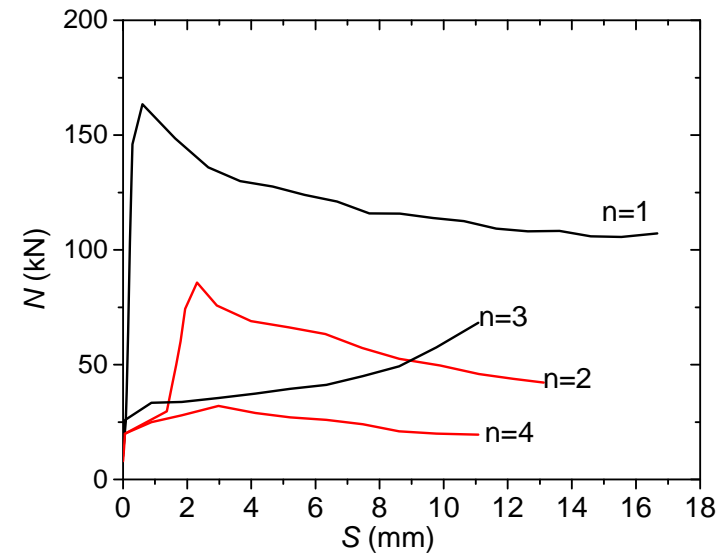

(a) A-1-c

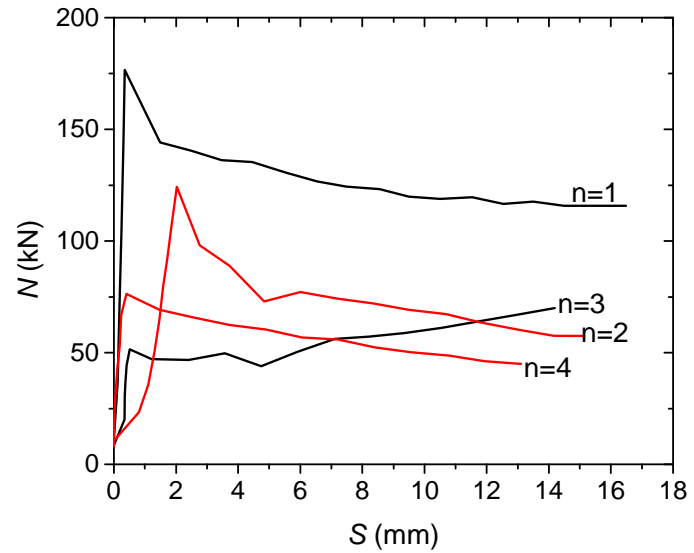

(a) C-5-C

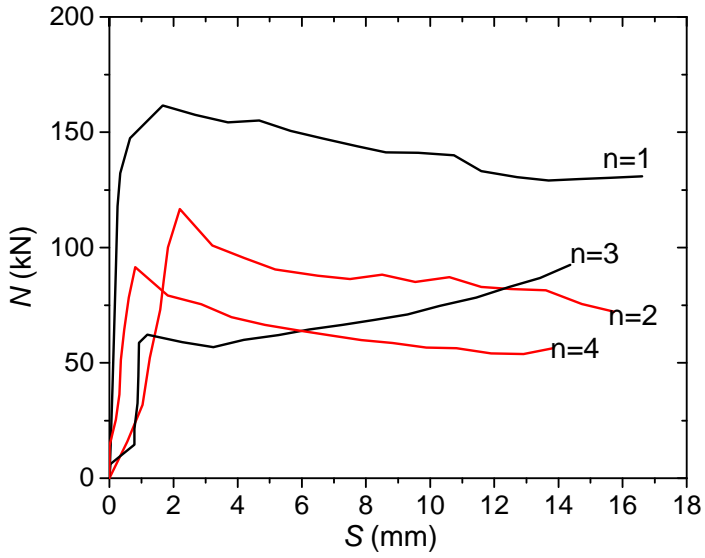

(b) A-3-a

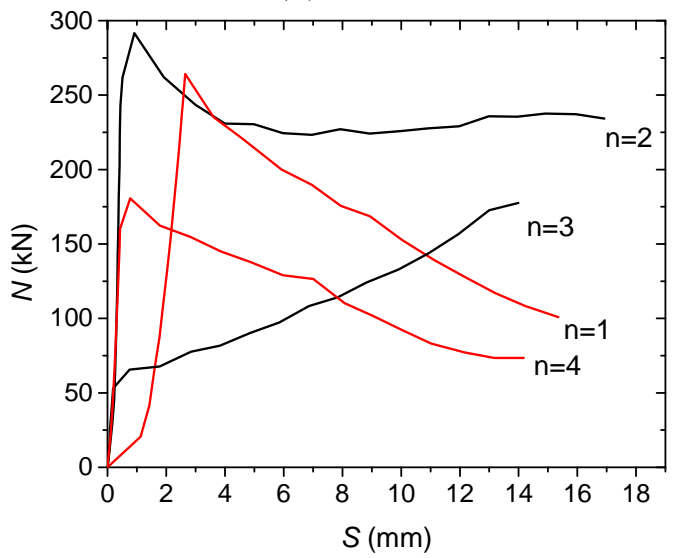

(b) D-6-a

Figure 9. Load $(N)$-Slip $(S)$ Curves: Repeated Push-out Test

\section{BOND STRENGTH PREDICTION}

Through the analysis of main factors on bond strength of LACFSTs, it can be concluded that the surface roughness, the slenderness ratio, and the diameter-to-thickness ratio are the main factors affecting behavior of the LACFST. The influence of concrete strength is not considered when calculating bond strength because of its smaller impact. Effects of concrete pouring and curing method on the bond strength cannot be ignored; but the influences of the two are not quantitatively considered due to the complexity of actual construction situations. Generally, the pouring and curing quality of concrete can be ensured according to the standard process of construction. In the process of a push-out test, the concrete is restrained by the steel tube, and the steel properties affect the bond strength. Some bond slip studies of normal CFSTs considered this by adopting a confinement coefficient and a steel area ratio [37], but the influence of steel area ratio and confinement coefficient are actually consistent when the effect of concrete strength is not considered. In practical engineering, the restraining effect of the steel tube on the concrete should be ensured because a low confinement coefficient causes local buckling. Meanwhile, slip occurs only with difficulty under conditions of obvious radial deformation of the steel tube caused by local buckling. The steel tube is required to deliver sufficient constraint to the concrete, otherwise it is not meaningful to discuss the interface bond slip. As shown in Figure 4, all of the specimens had no local buckling in the testing process. Based on the previous research into LACFSTs, a confinement coefficient larger than 1.0 was suggested to ensure the constraint effect [38]. Therefore, 
the influence of steel properties was not considered in this discussion. In addition, the influence of other factors is considered by a safety coefficient.

With reference to the previous studies on normal CFSTs, a bond strength calculation formula was proposed according to the regression on the test results:

$\tau=\gamma \times k\left[4.1625-0.2226\left(\frac{L}{d}\right)-0.0477\left(\frac{D}{t}\right)\right]$

Where, $\tau$ is the bond strength of an LACFST; $\gamma$ is the safety coefficient; $k$ is the influence coefficient for steel surface condition; $l$ is the length of the interface; $t$ is the thickness of the steel tube; $d$ and $D$ are the internal and external diameters of the steel tube, respectively. According to the suggestion arising from normal CFST studies, $\gamma$ takes the value of 0.9 considering the errors in fabrication and unfavorable curing condition; $k$ takes the value of 1.3 for a rusty surface without any de-rusting, 1.0 for a rusty surface with manual de-rusting, and 0.75 for rustless surfaces or rusty surfaces subjected to mechanical de-rusting [37].

The results from the use of Equation (1) are listed in Table 3 and compared to the test results. In the table, specimens B-4 and C-5 were not analyzed because the condition is not adopted in engineering practice. The average ratio of calculated bond strength to the test value was 0.973 with a standard deviation value of 0.033. The comparison shows that the results from Eq. 1 are accurate, and matched test data.

Table 3. Comparison of Test and Calculation Results

\begin{tabular}{|c|c|c|c|c|c|c|c|c|}
\hline \multirow{2}{*}{ Specimen } & \multirow{2}{*}{$\begin{array}{l}\text { Size (mm) } \\
D \times t \times L\end{array}$} & \multirow{2}{*}{$L / d$} & \multirow{2}{*}{$D / t$} & \multirow{2}{*}{$\gamma$} & \multirow{2}{*}{$k$} & \multicolumn{2}{|c|}{ Bond strength (MPa) } & \multirow{2}{*}{$\tau_{2} / \tau_{1}$} \\
\hline & & & & & & $\operatorname{Test}\left(\tau_{1}\right)$ & Calculation $\left(\tau_{2}\right)$ & \\
\hline A-1 & $114 \times 4 \times 350$ & 3.30 & 28.5 & 0.9 & 0.75 & 1.42 & 1.396 & 0.983 \\
\hline A-2 & $114 \times 4 \times 350$ & 3.30 & 28.5 & 0.9 & 0.75 & 1.52 & 1.396 & 0.919 \\
\hline A-3 & $114 \times 4 \times 350$ & 3.30 & 28.5 & 0.9 & 0.75 & 1.39 & 1.396 & 1.004 \\
\hline D-6 & $114 \times 4 \times 350$ & 3.30 & 28.5 & 0.9 & 1.3 & 2.45 & 2.420 & 0.988 \\
\hline E-7 & $114 \times 4 \times 490$ & 4.62 & 28.5 & 0.9 & 1.3 & 2.09 & 2.076 & 0.993 \\
\hline E-8 & $114 \times 4 \times 780$ & 7.36 & 28.5 & 0.9 & 1.3 & 1.46 & 1.363 & 0.933 \\
\hline F-9 & $114 \times 2.5 \times 350$ & 3.30 & 45.6 & 0.9 & 1.3 & 1.48 & 1.466 & 0.990 \\
\hline \multicolumn{8}{|c|}{ Average } & 0.973 \\
\hline
\end{tabular}

\section{CONCLUSIONS}

The factors influencing bond strength were different from those found in studies of normal concrete-filled steel tubes. To clarify these reasons for this, a further study is needed. According to the test results and studies of the references, the following conclusions were obtained.

(1) The push-out tests on lightweight aggregate concrete-filled steel tubes gave two types of load-slip curves which either had obvious peaks or not. It depended on whether the friction after slip being smaller than the initial bond force or not. Each type of curve had three trends after ultimate load due to the degree of macro-dimensional deviation.

(2) According to these test, the bond strength was independent of the lightweight aggregate concrete strength. On the other hand, higher diameter-to-thickness ratios resulted in smaller bond strength. Moreover, a good quality of concrete vibration and curing could improve the bond strength. 
(3) The repeated push-out test results showed that the ultimate load and bond strength corresponding to the first time push-out were the largest. In the same push-out direction, the ultimate load and bond strength decreased in time. After the ultimate load was conducted, the load-slip curves for push-out in the same direction were similar. These data were consistent with evidence from studies on normal concrete filled steel tubes.

(4) A calculation method of bond strength was proposed based on the test results. A comparison between test results and calculation results showed that the method was accurate when calculating the bond strength of lightweight aggregate concrete-filled steel tubes.

\section{ACKNOWLEDGMENTS}

The authors appreciate the support of The National Natural Science Fund of China (No.51208176), the Fundamental Research Funds for the Central Universities (2018B17414) and the Qing Lan Project. Besides, the first author would like to thank to Meijo University for the Invitation Fellowship Program.

\section{REFERENCES}

[1] Chen, B.C. and Wang, T.L., “Overview of Concrete Filled Steel Tube Arch Bridges in China”, Practice periodical on structural design and construction, 2009, Vol.14, No.2, pp. 70-80.

[2] Xu, T., Xiang, T., Zhao, R., and Zhan, Y., "Nonlinear Finite Element Analysis of Circular Concrete-Filled Steel Tube Structures”, Structural Engineering and Mechanics, 2010, Vol.35, No.3, pp.315-333.

[3] Morino, S., and Tsuda, K., "Design and Construction of Concrete-Filled Steel Tube Column System in Japan”, Earthquake Engineering and Engineering Seismology, 2002, Vol.4, No.1, pp. 51-73.

[4] Han, L.H., Hou, C.C., and Wang, Q.L., "Behavior of Circular CFST Stub Columns under Sustained Load and Chloride Corrosion”, Journal of Constructional Steel Research, 2014, Vol.103, pp.23-36.

[5] Ge, H.B., Susantha, K.A.S., Satake, Y. and Usami T., "Seismic Demand Predictions of Concrete-filled Steel Box Columns”, Engineering Structures, 2003, Vol.25, No.3, pp. 337-345.

[6] Zhou, X., Yan, B., and Liu, J., "Behavior of Square Tubed Steel Reinforced-Concrete (SRC) Columns under Eccentric Compression”, Thin-Walled Structures, 2015, Vol.91, pp.129-138.

[7] Assi, I.M., Qudeimat, E.M., and Hunaiti, Y.M., "Ultimate Moment Capacity of Foamed and Lightweight Aggregate Concrete-Filled Steel Tubes”, Steel and Composite Structures, 2003, Vol.3, No.3, pp.199-212.

[8] Fu, Z.Q., Ji, B.H., Lv, L., and Zhou, W.J., "Behavior of Lightweight Aggregate Concrete Filled Steel Tubular Slender Columns under Axial Compression”, Advanced Steel Construction, 2011, Vol.7, No.2, pp.144-156.

[9] Sohel, K.M.A., Liew, J.R., and Koh, C.G., "Numerical Modelling of Lightweight Steel-Concrete-Steel Sandwich Composite Beams Subjected to Impact”, Thin-Walled Structures, 2015, Vol. 94, pp.135-146.

[10] Mossahebi, N., Yakel, A., and Azizinamini, A., "Experimental Investigation of a Bridge Girder Made of Steel Tube Filled with Concrete”, Journal of Constructional Steel Research, 2005, Vol.61, No.3, pp.371-386. 
[11] Dai, J.G., Tamon, U. and Yasuhiko, S., "Development of the Nonlinear Bond Stress-Slip Model of Fiber Reinforced Plastics Sheet-Concrete Interfaces with a Simple Method", Journal of Composites for Construction, 2005, Vol.9, No.1, pp.52-62.

[12] Roeder, C.W., Cameron, B., and Brown, C.B., "Composite Action in Concrete Filled Tubes”, Journal of Structural Engineering, 1999, Vol.125, No.5, pp.477-484.

[13] Tao, Z., Song, T.Y., Uy, B., and Han, L.H., "Bond Behavior in Concrete-Filled Steel Tubes”, Journal of Constructional Steel Research, 2016, Vol.120, pp.81-93.

[14] Al-Mosawe, A., Al-Mahaidi, R., and Zhao, X.L., "Bond Behaviour between CFRP Laminates and Steel Members under Different Loading Rates”, Composite Structures, 2016, Vol.148, pp.236-251.

[15] Xie, T., and Ozbakkaloglu, T., "Behavior of Recycled Aggregate Concrete-Filled Basalt and Carbon FRP Tubes”, Construction and Building Materials, 2016, Vol.105, pp.132-143..

[16] Tahir, M.M., Shek, P.N., and Tan, C.S., "Push-off Tests on Pin-connected Shear Studs with Composite Steel-Concrete Beams”, Construction and Building Materials, 2009, Vol. 23, No.9, pp. 3024-3033.

[17] Chen, L., Dai, J., Jin, Q., Chen, L., and Liu, X., "Refining Bond-Slip Constitutive Relationship between Checkered Steel Tube and Concrete”, Construction and Building Materials, 2015, Vol.79, pp.153-164.

[18] Yan, J.B., Liew, J.R., Sohel, K.M.A. and Zhang, M.H., "Push-out Tests on J-hook Connectors in Steel-Concrete-Steel Sandwich Structure”, Materials and Structures, 2014 , Vol.47, No.10, pp.1693-1714.

[19] Chen, Y., Feng, R., Shao, Y., and Zhang, X., "Bond-slip behaviour of concrete-filled stainless steel circular hollow section tubes”, Journal of Constructional Steel Research, 2017, Vol.130, pp. 248-263.

[20] Abendeh, R., Ahmad, H. S., and Hunaiti, Y. M., "Experimental studies on the behavior of concrete-filled steel tubes incorporating crumb rubber”, Journal of Constructional Steel Research, 2016, Vol. 122, pp. 251-260.

[21] Aly, T., Elchalakani, M., Thayalan, P., and Patnaikuni, I., "Incremental collapse threshold for pushout resistance of circular concrete filled steel tubular columns", Journal of Constructional Steel Research, 2010, Vol. 66, No. 1, pp. 11-18.

[22] Qu, X., Chen, Z., Nethercot, D. A., Gardner, L., and Theofanous, M., "Load-reversed push-out tests on rectangular cfst columns”, Journal of Constructional Steel Research, 2013, Vol. 81, No. 3, pp. 35-43.

[23] PetrusClotilda, Hamidhanizah, A., IbrahimAzmi, and Davylyn, N. J., "Bond strength in concrete filled built-up steel tube columns with tab stiffeners”, Canadian Journal of Civil Engineering, 2011, Vol. 38, No. 6, pp. 627-637.

[24] Nezamian, A., Almahaidi, R., and Grundy, P., "Bond strength of concrete plugs embedded in tubular steel piles under”, Canadian Journal of Civil Engineering, 2006, Vol. 33, No. 2, pp. 111-125.

[25] Xu, C., Huang, C., Jiang, D., and Song, Y., "Push-out test of pre-stressing concrete filled circular steel tube columns by means of expansive cement”, Construction \& Building Materials, 2009, Vol. 23, No. 1, pp. 491-497.

[26] Mouli, M., and Khelafi, H., "Strength of short composite rectangular hollow section columns filled with lightweight aggregate concrete”, Engineering Structures, 2007, Vol. 29, No. 8, pp. 1791-1797.

[27] Eurocode 4. Design of composite steel and concrete structures. Part 1-1: General rules and rules for buildings, BSI. 2004.

[28] AASHTO. "AASHTO-LRFD Bridge design guide specifications for GFRP-reinforced concrete bridge decks and traffic railings.” American Association of State Highway and Transportation Officials, Washington, DC. 2009. 
[29] "Recommendations for design and construction of concrete filled steel tubular structure", Tokyo: Architectural Institute of Japan. 1997.

[30] CECS $28: 2012$, “Technical specification for concrete-filled steel tubular structures”, The Engineering Construction Association of China, 2012. (In Chinese)

[31] GB/T228-2002, “Metallic Materials-Tensile Testing at Ambient Temperature”, The National Standard of China, 2002. (In Chinese)

[32] Virdi, K. S., "Bond Strength in Concrete Filled Steel Tubes”, Int. Assoc. for Bridge \& Structural Engineering, 1980, Vol.3, pp.125-139.

[33] Liu, Y.J., Liu, J.P., and Chi, J.J., "Shear Bond Behaviors at Interface of Concrete-Filled Steel Tube”, Journal of Guangxi University (Natural Science Edition), 2010, Vol.35, No.1, pp. 17-23. (In Chinese)

[34] Shakir-Khalil, H., "Pushout Strength of Concrete-Filled Steel Hollow Section Tubes", The Structural Engineering, 1993, Vol.71, No.13, pp.230-233.

[35] Xue, L.H., and Cai, S.H., "Bond Strength at the Interface of Concrete-Filled Steel Tubular Columns: part I”, Building Science, 1996, Vol.12, No.3, pp.22-8. (In Chinese)

[36] Xue, L.H., and Cai, S.H., "The Influence of Load Eccentricity on Bond Strength at the Interface of Concrete-Filled Steel Tube Columns”, Building Science, 1997, Vol.13, No.2, pp.22-25. (In Chinese)

[37] Xu, J.J., Chen ,Z.P., Xue, J.Y., and SU, Y.S., "Failure Mechanism of Interface Bond Behavior Between Circular Steel Tube and Recycled Aggregate Concrete by Push-out Test”, Journal of Building Structures, 2013, Vol.34, No.7, pp.148-157. (In Chinese)

[38] Fu, Z.Q., Ji, B.H., Zhou, Y., and Wang, X.L., “An Experimental Behavior of Lightweight Aggregate Concrete Filled Steel Tubular Stub under Axial Compression”, In GeoHunan Int. Conf., 2011, pp.24-32. 